\title{
Prevalence of asthma and chronic obstructive pulmonary disease in Aboriginal and non-Aboriginal populations: A systematic review and meta-analysis of epidemiological studies
}

\author{
Maria B Ospina MSc PhD(candidate) ${ }^{1}$, Donald C Voaklander PhD ${ }^{1}$, Michael K Stickland PhD², Malcolm King PhD², \\ Ambikaipakan Senthilselvan PhD ${ }^{1}$, Brian H Rowe MD MSc CCFP(EM) FCCP',3
}

\begin{abstract}
MB Ospina, DC Voaklander, MK Stickland, M King, A Senthilselvan, BH Rowe. Prevalence of asthma and chronic obstructive pulmonary disease in Aboriginal and non-Aboriginal populations: A systematic review and meta-analysis of epidemiological studies. Can Respir J 2012;19(6):355-360.
\end{abstract}

BACKGROUND: Asthma and chronic obstructive pulmonary disease (COPD) have considerable potential for inequities in diagnosis and treatment, thereby affecting vulnerable groups.

OBJECTIVE: To evaluate differences in asthma and COPD prevalence between adult Aboriginal and non-Aboriginal populations.

METHODS: MEDLINE, EMBASE, specialized databases and the grey literature up to October 2011 were searched to identify epidemiological studies comparing asthma and COPD prevalence between Aboriginal and non-Aboriginal adult populations. Prevalence ORs (PORs) and 95\% CIs were calculated in a random-effects meta-analysis.

RESULTS: Of 132 studies, eight contained relevant data. Aboriginal populations included Native Americans, Canadian Aboriginals, Australian Aboriginals and New Zealand Maori. Overall, Aboriginals were more likely to report having asthma than non-Aboriginals (POR 1.41 [95\% CI 1.23 to 1.60$]$ ), particularly among Canadian Aboriginals (POR 1.80 [95\% CI 1.68 to 1.93]), Native Americans (POR 1.41 [95\% CI 1.13 to 1.76]) and Maori (POR 1.64 [95\% CI 1.40 to 1.91]). Australian Aboriginals were less likely to report asthma (POR 0.49 [95\% CI 0.28 to 0.86]). Sex differences in asthma prevalence between Aboriginals and their non-Aboriginal counterparts were not identified. One study compared COPD prevalence between Native and non-Native Americans, with similar rates in both groups (POR 1.08 [95\% CI 0.81 to 1.44$]$ ).

CONCLUSIONS: Differences in asthma prevalence between Aboriginal and non-Aboriginal populations exist in a variety of countries. Studies comparing COPD prevalence between Aboriginal and non-Aboriginal populations are scarce. Further investigation is needed to identify and account for factors associated with respiratory health inequalities among Aboriginal peoples.

Key Words: Aboriginal; Asthma; Chronic obstructive pulmonary disease; Epidemiology; Prevalence; Systematic review

\author{
La prévalence d'asthme et de maladie pulmonaire \\ obstructive chronique au sein des peuples \\ autochtones et non autochtones : une analyse \\ systématique et une méta-analyse d'études \\ épidémiologiques
}

HISTORIQUE : L'asthme et la maladie pulmonaire obstructive chronique (MPOC) présentent un potentiel considérable de disparités de diagnostic et de traitement, qui touche les groupes vulnérables.

OBJECTIF : Évaluer les différences de prévalence d'asthme et de MPOC au sein de peuples autochtones et non autochtones adultes.

MÉTHODOLOGIE : Les auteurs ont effectué des recherches dans MEDLINE, EMBASE, des bases de données spécialisées et des publications grises jusqu’à octobre 2011 pour repérer des études épidémiologiques comparant la prévalence d'asthme et de MPOC entre les peuples autochtones et non autochtones adultes. Ils ont calculé les RRR de prévalence (RRRP) et les $95 \%$ IC dans une méta-analyse à effets aléatoires.

RÉSULTATS : Sur les 132 études, huit contenaient des données pertinentes. Les peuples autochtones incluaient des Autochtones américains, canadiens et australiens ainsi que des Maoris de la Nouvelle-Zélande. Dans l'ensemble, les Autochtones étaient plus susceptibles de déclarer de l'asthme que les non-Autochtones (RRRP 1,41 [95 \% IC 1,23 à 1,60]), notamment les Autochtones canadiens (RRRP 1,80 [95\% IC 1,68 à 1,93]) et américains (RRRP 1,41 [95\% IC 1,13 à 1,76]) et les Maoris (RRRP 1,64 [95 \% IC 1,40 à 1,91]). Les Autochtones australiens étaient moins susceptibles de déclarer de l'asthme (RRRP 0,49 [95 \% IC 0,28 à $0,86]$ ). Les chercheurs n'ont pas constaté de différence de prévalence d'asthme selon le sexe entre les Autochtones et leurs homologues non autochtones. Une étude a comparé la prévalence de MPOC entre les Autochtones et non-Autochtones américains et a obtenu des taux similaires dans les deux groupes (RRRP 1,08 [95 \% IC 0,81 à 1,44]).

CONCLUSIONS : Il existe des différences dans la prévalence d'asthme au sein des peuples autochtones et non autochtones de divers pays. Peu d'études portent sur la comparaison de la prévalence de MPOC entre les peuples autochtones et non autochtones. D'autres explorations s'imposent pour déterminer et prendre en compte les facteurs associés aux disparités en santé au sein des peuples autochtones.
$\mathrm{O}$ bstructive lung diseases, such as asthma and chronic obstructive pulmonary disease (COPD), are respiratory conditions that impose an enormous burden on society. Currently, an estimated 300 million people worldwide have asthma (1) and up to $10 \%$ of adults older than 40 years of age may have $\operatorname{COPD}(2,3)$, with perhaps millions remaining undiagnosed. These conditions carry the potential for inequities in diagnosis, treatment and access to health services, thereby affecting vulnerable groups in society $(4,5)$. Inequalities in health status occur when one group in the population experiences differences in health outcomes compared with another group that often result from social, cultural, economic, environmental or geographical influences (6) such as sex, education level, occupation, income, employment status, refugee background, religious beliefs, disability, rurality, ethnicity and Aboriginal identity (7).

Ethnicity, particularly Aboriginal ethnicity, is a well-recognized factor that contributes to health and social inequalities worldwide (8-10). Systematic reviews of epidemiological research on Aboriginal physical and mental health $(11,12)$ have consistently shown that,

${ }^{1}$ School of Public Health; ${ }^{2}$ Division of Pulmonary Medicine; ${ }^{3}$ Department of Emergency Medicine, Faculty of Medicine $\mathcal{E}$ Dentistry,

University of Alberta, Edmonton, Alberta

Correspondence: Dr Brian H Rowe, Department of Emergency Medicine, Room 1G1.43 WMC, University of Alberta Hospital,

8440-112th Street, Edmonton, Alberta T6G 2B7. Telephone 780-407-6707, fax 780-407-3982, e-mail brian.rowe@ualberta.ca 
compared with the general population, Aboriginal peoples experience a considerable gap in their health status that negatively impacts their life expectancy and worsens the burden of many conditions including respiratory diseases. Inequalities in the frequency of asthma and COPD among Aboriginal peoples of multiple ethnicities and nonAboriginal populations have not been systematically documented. With these considerations in mind, we conducted a systematic review of epidemiological studies to compare the prevalence of asthma and COPD between Aboriginal and non-Aboriginal adult populations in a variety of settings and countries. The systematic review was also intended to establish whether there is evidence in the scientific literature of a global pattern of inequality in respiratory health affecting Aboriginal populations.

\section{METHODS}

An a priori protocol for the systematic review was used to define the search strategy, set the study selection criteria, outline quality assessment and data extraction procedures, and plan the analysis of the study results.

\section{Search strategy}

The MEDLINE, EMBASE, Circumpolar Health Bibliographic Database and the Native Health Databases were searched from inception date to October 2011. For optimum sensitivity, a broad search strategy that included a combination of medical subject headings and text words was used: (respiratory tract diseases OR pulmonary disease chronic obstructive, lung diseases, obstructive, respiratory function tests OR asthma OR bronchoconstriction) AND (Aborigine* OR Aborigi* OR Aboriginal* OR Indigenous people* OR Indigenous population* OR Maori* OR Inuit* OR Eskimo* OR Aleut* OR Native American* OR Native Canadian OR Native Canadian* OR Native Alaskan* OR American Native* OR Alaskan Native* OR Canadian Native* OR American Indian* or Canadian Indian* OR Amerind* OR Inupiats OR Inupiat OR Kalaallits OR Kalaallit OR Tribes OR Natives OR Indigenous OR First Nations OR Metis). In addition, the references of relevant studies were scanned and selected. Aboriginal health journals were manually searched for additional published work. Internet-based searches were conducted to identify unpublished work. No restrictions were imposed in terms of language or publication status.

\section{Study selection}

Studies were included if they were observational analytical studies that compared asthma or COPD prevalence between Aboriginal and non-Aboriginal adult populations. In the current review, the term 'Aboriginal' refers to an ethnic group with a defined identity and affiliation who inhabit a territory or geographical region with which they have the earliest known historical connection (13). Studies including Aboriginal populations from Australia, New Zealand, United States, Canada and other countries of the Northern circumpolar region, such as Denmark, Norway and Sweden, were eligible because Aboriginal health disadvantages in these countries compared with the general population have been largely documented in the scientific literature $(14,15)$. The primary outcomes of interest were the prevalence of asthma and COPD, defined as the number of (old and new) asthma and COPD cases during a particular period of time. Studies reporting exclusively on the frequency of individual symptoms (eg, wheezing, cough, dyspnea) or other chronic respiratory conditions were excluded from the review. Multiple publication data (16) were incorporated into the information reported in the main publication. Two reviewers independently screened each citation and obtained full-text copies of potentially relevant studies, which were further assessed using a standard form that outlined the eligibility criteria. Disagreements in study selection were resolved by consensus.

\section{Quality assessment}

Study quality was assessed using an eight-item rating system (17) that evaluated the methods of sampling, sampling frame, sample size, outcome measurement, outcome assessment, response rate, statistical reporting and interpretation of study results. Both individual component and scale approaches to quality assessment were used. Overall quality scores ranged from 0 to 8 ( 0 to 3 points $=$ poor; 4 to 6 points $=$ moderate; and 7 to 8 points $=$ high) $(17)$. Two reviewers independently assessed study quality, with disagreements resolved by consensus.

\section{Data extraction}

One reviewer extracted the following information onto a pretested data extraction form and double-entered it for accuracy: country, publication year, study design, study condition (ie, asthma, COPD), observation period, geographical location (ie, rural, urban, mixed), study settings (ie, national, regional, municipality, remote community), Aboriginal group, reference group, age, sex, case assessment methods, response rates and prevalence rates. If the studies included more than one comparison group, data from the predominant reference group were extracted. Attempts were made to contact the senior authors of studies included in the review to obtain additional data or data not reported in the publications. Graphical data were converted using GraphClick for Macintosh (Apple Inc, USA) and indicated as such in the presentation of the results.

\section{Data analysis}

Agreement among reviewers in study selection and quality assessment is reported using the Kappa ( $\kappa)$ statistic (18) and 95\% CIs. Asthma and COPD prevalence estimates were reported separately as percentages with $95 \%$ CIs. For each respiratory condition, prevalence ORs (PORs) and 95\% CIs were calculated for Aboriginal groups with reference to a non-Aboriginal group. A POR value $>1$ indicated that the odds of having the respiratory condition of interest were higher among Aboriginal peoples compared with the non-Aboriginal reference group. Meta-analyses were undertaken using the method of inversevariance weighting under a DerSimonian and Laird random effects model $(19,20)$ in the presence of small or moderate statistical heterogeneity (indicated by $\mathrm{P}<0.05$ in the Cochran's $\chi^{2}$ test $(21)$ and an $\mathrm{I}^{2}$ statistic $<74 \%$ [22]). Methodological and clinical characteristics (eg, participants, methods of case identification and outcome ascertainment) were explored qualitatively as potential sources of heterogeneity. Sensitivity analysis according to study quality and subgroup analysis according to smoking status, age and sex were planned; however, only the latter was feasible because none of the studies reported prevalence data according to smoking status or age group, and the methodological quality was relatively homogeneous across the studies. Statistical analyses were undertaken using Predictive Analysis Software Statistics for Macintosh (PASW version 18.0, SPSS, IBM Corporation, USA) and Review Manager (RevMan version 5.0. Copenhagen: The Nordic Cochrane Centre, The Cochrane Collaboration, 2008).

\section{Search results}

\section{RESULTS}

The searches identified 2136 citations. After screening of titles and abstracts, 132 references were judged as potentially relevant, 10 of which satisfied the eligibility criteria. Of these, two $(23,24)$ were multiple publications from one report (25). Therefore, the review included eight cross-sectional analytical studies (25-32) reported in 10 publications (Figure 1). The level of agreement among reviewers for study selection was substantial ( $\kappa=0.86$ [95\% CI 0.77 to 0.95$]$ ). The complete list of excluded studies and reasons for exclusion are available on request.

\section{Study characteristics}

Table 1 summarizes the main characteristics and results of the individual studies. The median year of publication of the studies was 2008 (interquartile range 1996 to 2009). Four studies $(25,27,30,31)$ presented epidemiological data for Aboriginal populations from both urban and rural settings. Two studies $(26,32)$ collected epidemiological data from Aboriginals in rural settings exclusively, whereas two studies $(28,29)$ 
did not explicitly report the setting for which their data were applicable. Ethnicities represented in the studies were Native Americans $(28,30,31)$, Canadian Aboriginals (27,29), Australian Aboriginals $(26,32)$ and New Zealand Maori (25). Aboriginal status was defined by self-identification in five studies $(25,27-30)$ and by community attachment to an Aboriginal group in two studies (26,31). One study did not provide a definition of Aboriginal status (32). Non-Aboriginal reference groups consisted of individuals described as 'whites' $(30,31)$, 'non-Hispanic whites' (28), individuals of 'European descent' (26) and, in some instances, were described generically as 'non-Aboriginals' $(25,27,29,32)$.

All of the studies reported data to allow comparisons of asthma prevalence rates between Aboriginal and non-Aboriginal populations. One study provided data on the prevalence of COPD in Aboriginals compared with a reference group of non-Aboriginals (31). The reporting of asthma frequency outcomes used at least one of the following criteria: self-report of doctor- or other health professional-diagnosed asthma (26,31); history of wheeze or shortness of breath in the previous 12 months (25,32); asthma medication use (25); and a positive result in a bronchial hyper-responsiveness test (32). The reporting of COPD frequency was based on self-report of doctor or other health professional diagnosis regarding the presence of emphysema or chronic bronchitis (31).

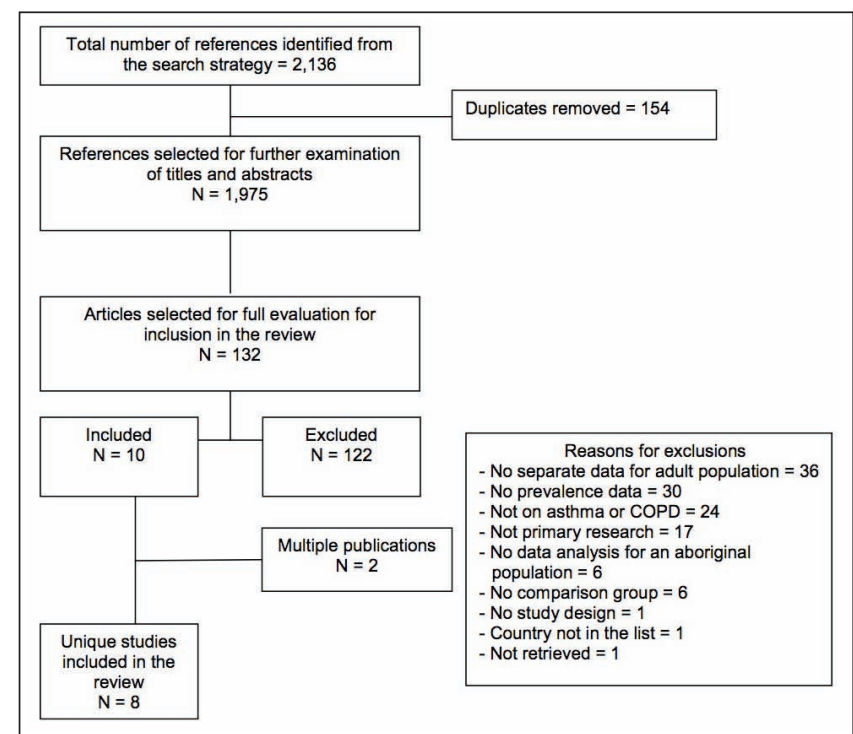

Figure 1) PRISMA flow diagram for identification of studies. COPD Chronic obstructive pulmonary disease

\section{TABLE 1}

Studies comparing asthma and chronic obstructive pulmonary disease (COPD) prevalence between adult Aboriginal and non-Aboriginal populations

\begin{tabular}{|c|c|c|c|}
\hline \multirow{2}{*}{$\begin{array}{l}\text { Author (reference), } \\
\text { year; country }\end{array}$} & \multirow[b]{2}{*}{ Study participant characteristics } & \multicolumn{2}{|r|}{ Prevalence rate } \\
\hline & & $\%(95 \% \mathrm{Cl})$ & According to sex, $\%(95 \% \mathrm{Cl})$ \\
\hline \multirow[t]{2}{*}{$\begin{array}{l}\text { Bremner et al (26), } \\
\text { 1998; Australia }\end{array}$} & $\begin{array}{l}\text { Australian Aboriginals (Western Australia); } \\
\text { Australians of European descent }\end{array}$ & $\begin{array}{l}\text { Asthma: lifetime: Aboriginals: } \\
12(6.3-17.7)\end{array}$ & $\begin{array}{l}\text { Asthma: Aboriginals: male } 8.5(14-15.6) \\
\text { female } 15.2(6.5-23.8)\end{array}$ \\
\hline & $\begin{array}{l}\text { Total: } n=677 ; \text { male, } n=336 ; \text { female, } n=341 \\
\text { Aboriginals: } n=125 ; \text { male, } n=59 ; \text { female, } n=66\end{array}$ & Reference: 16.7 (13.6-19.8) & $\begin{array}{l}\text { Reference: male } 15.5(11.3-19.8) \\
\text { female } 17.8(13.3-22.3)\end{array}$ \\
\hline \multirow[t]{2}{*}{$\begin{array}{l}\text { Crane et al (25), } \\
\text { 1994; New Zealand }\end{array}$} & $\begin{array}{l}\text { New Zealand Maori; non-Polynesians } \\
\text { Total, n=11,567 (male/female } n \text { not reported) }\end{array}$ & $\begin{array}{l}\text { Asthma: } 1 \text { year: Aboriginals: } \\
21.9(19.4-24.3)\end{array}$ & Not reported \\
\hline & Aboriginals, $\mathrm{n}=1057$ (male/female $\mathrm{n}$ not reported) & Reference: 14.6 (13.9-15.3) & \\
\hline \multirow[t]{5}{*}{$\begin{array}{l}\text { Garner et al (27), } \\
\text { 2010; Canada }\end{array}$} & $\begin{array}{l}\text { Canadian Aboriginals (First Nations, Métis and Inuit); } \\
\text { non-Aboriginal Canadians }\end{array}$ & $\begin{array}{l}\text { Asthma: lifetime } \\
\text { Aboriginals: } 12.9(12.4-13.3)^{*}\end{array}$ & Not reported \\
\hline & Total: $n=76,372 ;$ male 36,$653 ;$ female, $n=39,719$ & Inuit: $8.3(7.4-9.1)^{\star}$ & \\
\hline & Aboriginals: $n=20,086$; male, $n=9073$; female, $n=11,013$ & Métis: $13.9(13.1-14.7)^{\star}$ & \\
\hline & & First Nations: 14.1 (13.4-14.8)* & \\
\hline & & Reference: 7.8 (7.6-8) & \\
\hline \multirow{3}{*}{$\begin{array}{l}\text { Gorman and Chu } \\
\text { (28), 2009; } \\
\text { United States }\end{array}$} & Native Americans; non-Hispanic whites & Asthma: lifetime & Not reported \\
\hline & Total: $n=1,337,638 ;$ male $n=648,124 ;$ female $n=689,504$ & Aboriginals: 13.1 (12.6-13.6) & \\
\hline & Aboriginals: $n=17,931 ;$ male, $n=9386$; female, $n=8535$ & Reference: 8.2 (8.2-8.2) & \\
\hline \multirow{3}{*}{$\begin{array}{l}\text { Janz et al (29), 2009; } \\
\text { Canada }\end{array}$} & Canadian Aboriginals (Métis); non-Aboriginal Canadians & Asthma: lifetime & Asthma: Aboriginals: male 11 (9.9-12); \\
\hline & Total: $n=63,565 ;$ male, $n=30,965 ;$ female, $n=32,600$ & Aboriginals: 14 (13.2-14.8) & female 17 (15.8-18.2) \\
\hline & Aboriginals: $n=7279 ;$ male, $n=3385$; female, $n=3894$ & Reference: 8 (7.8-8.2) & Reference: NR \\
\hline \multirow{3}{*}{$\begin{array}{l}\text { Loveland et al (30), } \\
\text { 2008; United States }\end{array}$} & Native Americans (Montana); whites & Asthma: lifetime & Asthma: Aboriginals: male 6.7 (5.3-8.2); \\
\hline & Total: $n=26,737$; male, $n=13,094$; female, $n=13,643$ & Aboriginals: 10.5 (8.7-12.6) & female $14.1(12.1-16)$ \\
\hline & Aboriginals: $n=2411 ;$ male, $n=1174 ;$ female, $n=1237$ & Reference: 8.1 (7.7-8.4) & Reference: male 6.6 (6.2-7); female 9.5 (9-10) \\
\hline \multirow{5}{*}{$\begin{array}{l}\text { Pleis and Barnes } \\
\text { (31), 2008; } \\
\text { United States }\end{array}$} & $\begin{array}{l}\text { Native Americans (American Indian, Alaska Natives); } \\
\text { whites }\end{array}$ & $\begin{array}{l}\text { Asthma: lifetime } \\
\text { Aboriginals: } 11.7(9.7-14.2)\end{array}$ & Not reported \\
\hline & Total: $n=99,701 ;$ male, $n=48,062 ;$ female, $n=51,639$ & Reference: 10.1 (9.9-10.3) & \\
\hline & Aboriginals: $n=776$; male, $n=380$; female, $n=396$ & COPD: 1 year & \\
\hline & & Aboriginals: 6.4 (4.7-8.2) & \\
\hline & & Reference: 6 (5.9-6.1) & \\
\hline \multirow[t]{3}{*}{$\begin{array}{l}\text { Veale et al (32), } \\
\text { 1996; Australia }\end{array}$} & $\begin{array}{l}\text { Australian Aboriginals (Northern Territories and South } \\
\text { Australia); non-Aboriginal Australians }\end{array}$ & $\begin{array}{l}\text { Asthma: } 1 \text { year } \\
\text { Aboriginals: } 3.4(2-4.7)\end{array}$ & Not reported \\
\hline & Total, n=5735 (male/female $n$ not reported) & Reference: 8.3 (7.5-9.1) & \\
\hline & Aboriginals, n=715 (male/female $n$ not reported) & & \\
\hline
\end{tabular}

*Data extracted from graphs 


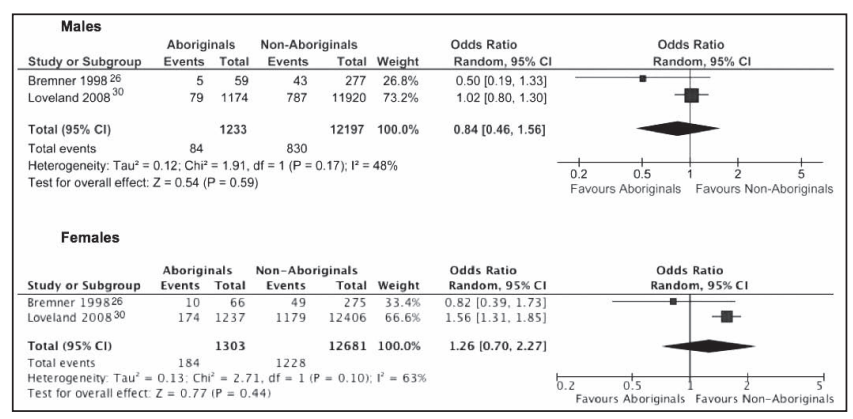

Figure 2) Summary of methodological characteristics of included studies

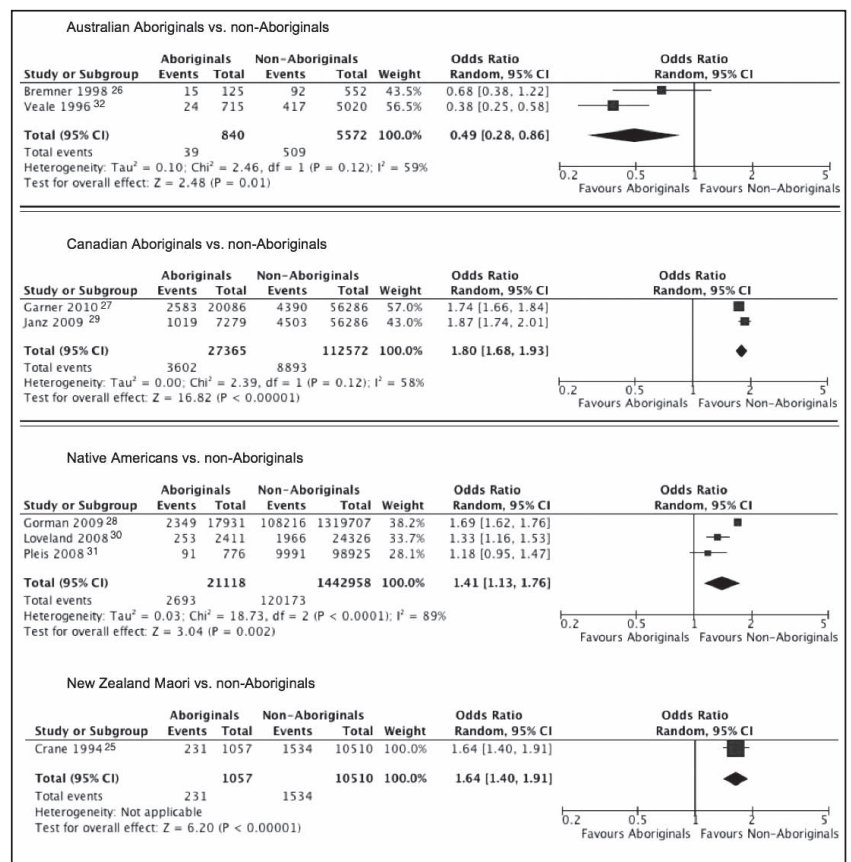

Figure 3) Meta-analysis of the comparison of asthma prevalence between Aboriginals and non-Aboriginals

\section{Quality assessment}

The overall methodological quality of the studies was moderate (median quality score 4 ; interquartile range 4 to 5). Figure 2 summarizes the overall methodological characteristics of the studies. All of the studies used probabilistic sampling to assemble the study population. Four studies used census data or other recruitment lists that were likely to introduce minimal selection bias. The sample size appeared to be adequate (ie, >1000 participants) in seven of eight studies; however, none of the studies reported sample size or power calculations. One study used objective and standardized criteria for assessing the presence of asthma, and five studies measured the outcome by trained and independent assessors; however, three studies reported response rates $>70 \%$. Three studies reported $95 \%$ CIs to indicate the level of confidence around the prevalence estimates. Five studies fully described the sociodemographic characteristics of participants to understand the applicability of the results. Finally, all studies except one disclosed funding source(s), with the majority being supported by government agencies.

\section{Asthma prevalence}

A random-effects meta-analysis of the eight studies (Figure 3) showed that Aboriginals have an odds of reporting asthma that is 1.41 times higher than that of non-Aboriginals (pooled POR 1.41 [95\% CI 1.23 to $1.60])$. There was evidence of heterogeneity $\left(\mathrm{P}<0.00001 ; \mathrm{I}^{2}=92 \%\right)$ and, therefore, possible causes of heterogeneity in overall asthma PORs were explored. All eight studies used a cross-sectional analytical

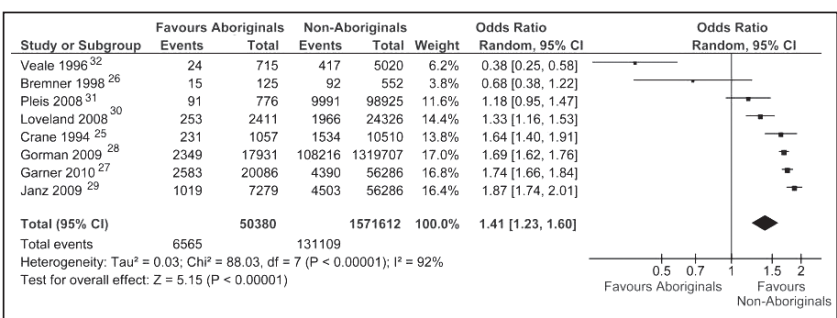

Figure 4) Subgroup analysis of the comparison of overall asthma prevalence between Aboriginals and non-Aboriginals according to Aboriginal type

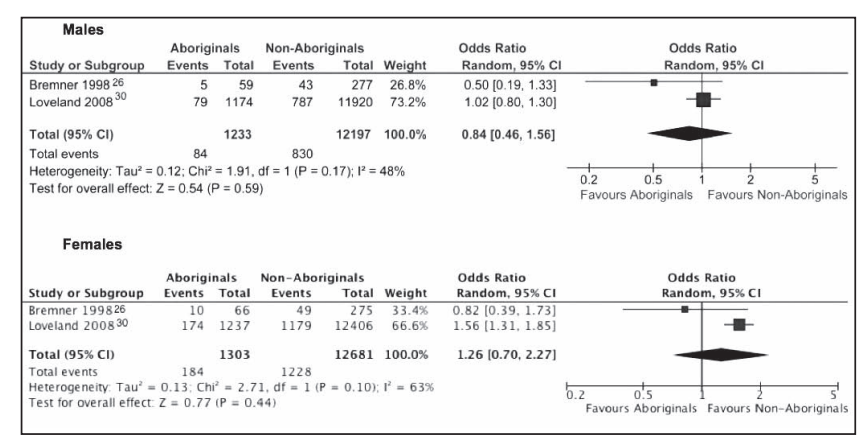

Figure 5) Meta-analysis of the comparison of sex-specific asthma prevalence between Aboriginals and non-Aboriginals

design based on survey data and had similar age distributions. There were differences, however, in the reporting of asthma prevalence estimates (lifetime [26-30] versus one-year [25,31,32] prevalence) and the methods to identify asthma cases (self-report questionnaires [25-31] versus bronchial hyper-responsiveness tests [32]). Subgroup analyses according to these factors did not remove the heterogeneity among the pooled studies in the overall POR. A subgroup analysis based on Aboriginal origin (Figure 4) showed moderate heterogeneity for studies that compared non-Aboriginals versus Australian Aboriginals $\left(\mathrm{P}=0.12 ; \mathrm{I}^{2}=59 \%\right)$ and non-Aboriginals versus Canadian Aboriginals $\left(\mathrm{P}=0.12 ; \mathrm{I}^{2}=58 \%\right)$. Heterogeneity in the prevalence measures across the studies that compared Native Americans versus non-Aboriginals remained high $\left(\mathrm{P}<0.0001 ; \mathrm{I}^{2}=89 \%\right)$. Subgroup analyses of moderately heterogeneous studies according to Aboriginal type showed that the odds of reporting asthma were significantly less in Australian Aboriginals compared with non-Aboriginal Australians (POR 0.49 [95\% CI 0.28 to 0.86]). The odds of reporting asthma were significantly higher in Canadian Aboriginals compared with non-Aboriginal Canadians (POR 1.80 [95\% CI 1.68 to 1.93$]$ ).

Data from two studies $(26,30)$ were pooled into a meta-analysis to compare sex-specific asthma prevalence between Aboriginal (Australian Aboriginals [26] and Native Americans [30]) and nonAboriginal populations (described as whites [30] or of European descent [26]) (Figure 5). There were no statistically significant differences in the reporting of asthma between Aboriginal and nonAboriginal males (POR 0.84 [95\% CI 0.46 to 1.56]) and between Aboriginal and non-Aboriginal females (POR 1.26 [95\% CI 0.70 to 2.27]). Both pooled results were moderately heterogeneous (males $\mathrm{P}=0.17 ; \mathrm{I}^{2}=48 \%$ and females $\mathrm{P}=0.10 ; \mathrm{I}^{2}=63 \%$ ).

\section{COPD prevalence}

Meta-analyses of comparisons of overall or sex-specific COPD prevalence between Aboriginals and non-Aboriginals were not conducted because only one cross-sectional analytical study (31) compared COPD prevalence in Native Americans (American Indian and Alaska Natives) with that of a reference group of individuals described as whites. Native Americans in that study were not statistically more likely to report COPD compared with individuals of white race (POR 1.08 [95\% CI 0.81 to 1.44$]$ ). 


\section{DISCUSSION}

The present systematic review summarized the best available evidence from epidemiological studies to compare the prevalence of asthma and COPD between adult Aboriginal and non-Aboriginal populations in a variety of settings and countries. Results from the review showed that, overall, Aboriginals - particularly Canadian Aboriginals, Native Americans and Maori - were more likely to report having asthma than non-Aboriginals. The review also identified only one study that compared the prevalence of COPD between Native and non-Native Americans, with similar rates in both groups. The present review was based on a systematic search of published and unpublished studies to avoid publication bias, and efforts were made to avoid selection bias by involving two reviewers in the screening and study selection stages. We used standardized techniques for quality appraisal of studies and undertook meta-analyses only when clinically and statistically appropriate. To our knowledge, the present study was the first comprehensive systematic review that used reproducible and systematic methods to evaluate the differences in the epidemiology of obstructive lung diseases between Aboriginal and non-Aboriginal populations. The scope of the review was limited to adult populations affected by asthma and COPD, and the results cannot be generalized to children. Asthma and COPD are associated with significant burden of morbidity and disability in adult populations and they both pose particular challenges for differential diagnosis and treatment that are not directly applicable to children.

Although only a limited number of studies were available, data in the present systematic review demonstrated the existence of significant differences in asthma prevalence between Aboriginal peoples and non-Aboriginal populations in industrialized countries. On the other hand, the evidence informing differences in COPD prevalence estimates between Aboriginal peoples and non-Aboriginal populations is scant. Yet, inequalities related to obstructive lung diseases are not homogeneous across all Aboriginal peoples; they all have distinct experiences of respiratory diseases and, therefore, inequalities must be understood within the diverse contexts within which Aboriginal communities live.

Meta-analyses of asthma prevalence between Aboriginal and nonAboriginal populations demonstrated that Aboriginals from Canada, the United States and New Zealand were more likely to report having asthma compared with other reference groups. Pooled analysis of data from two Australian studies, however, showed opposite results: Australian Aboriginals were significantly less likely to report having asthma. This result is not consistent with evidence from studies indicating that respiratory morbidity is much greater for Australian Aboriginals than for Australians of European descent (33), and that the gap in health status between Aboriginal peoples versus nonAboriginals is worse in Australia than in other Organisation for Economic Co-operation and Development countries with disadvantaged Aboriginal populations, including Canada, New Zealand and the United States $(13,34)$.

Discrepancies in results among the studies can be explained by several potential factors. One of the two studies included in the metaanalysis of asthma prevalence between Australian Aboriginal peoples and non-Aboriginals (32) was the only study that used a case definition of asthma based on medical examination and objective measures of bronchial hyper-responsiveness. Second, the lower prevalence of asthma in Australian Aboriginals, compared with other Aboriginal groups, could be due, at least in part, to differences in organizational factors related with the delivery of asthma diagnosis services for Aboriginal communities $(13,34)$. Similarly, environmental factors may play a role in explaining these results. More research is needed to confirm these hypotheses.

The methodological quality of the studies included in the review was relatively homogeneous, precluding a sensitivity analysis of variations in prevalence according to level of quality. Overall, the quality was rated as moderate; however, there are certain limitations in the methodological approach of the individual studies that should be considered. First, although the use of probabilistic sampling to assemble the study populations was likely to control for the effect of referral bias, only one-third of the studies had response rates $>70 \%$. Therefore, the potential impact of nonrespondent bias on the prevalence estimates cannot be disregarded. Second, although trained and independent assessors evaluated disease status in the majority of studies, the absence of standardized criteria and objective measures of asthma and COPD (except for one study of asthma) cast some doubt on the validity of the diagnoses. For example, some cases of COPD may be misdiagnosed as asthma; some asthma cases may result from other diagnoses (eg, vocal cord dysfunction, rhinitis, etc) and, in general, clinical diagnoses underestimate respiratory diagnoses (35). Finally, the individual studies did not report nor account for differences in the severity of symptoms and levels of disability between Aboriginal and non-Aboriginal groups.

Due to the lack of reporting of these variables in the individual studies, neither a qualitative or quantitative evaluation of the heterogeneity of the PORs through subgroup analyses according to smoking status or age categories was possible. Therefore, the present review cannot inform on whether differences in asthma prevalence among Aboriginals and non-Aboriginals remain after adjusting for differences in the distribution of these factors across the populations.

The contributing studies did not provide sufficient detail to analyze whether genetic, social (eg, socioeconomic level, geographical location) and/or environmental (eg, nutrition, crowding, housing, and indoor, outdoor and work-related air quality) factors $(1,36)$ could explain the differences in the epidemiology of asthma and COPD between Aboriginal and non-Aboriginal populations. The impact of inequities in the respiratory health status of Canadians (especially those of Aboriginal peoples) according to these and other variables warrants further investigation. Future epidemiological studies should improve our understanding of how Aboriginal status intersects with other social and health determinants to create inequitable conditions that may be associated with a higher incidence and prevalence of respiratory conditions.

The incorporation of an equity lens toward the evaluation of how respiratory problems affect Aboriginal communities within the existing respiratory health research capacity will have powerful implications for health services policy and planning. It constitutes an important contribution to the epidemiological study of respiratory diseases and an opportunity to address the disparities in respiratory health status that affect Aboriginal peoples in our society.

\section{CONCLUSION}

The present review helps to partially fill gaps in knowledge about the existence of differences in respiratory health status affecting Aboriginal peoples in industrialized countries. Asthma and COPD are a significant source of respiratory morbidity in Aboriginal communities. Particularly, Aboriginal peoples experience higher prevalence rates of asthma than non-Aboriginal populations. There is an urgent need for further epidemiological research evaluating the existence of COPD-related inequalities between Aboriginal and non-Aboriginal populations.

ACKNOWLEDGEMENTS: Dr Brian Rowe is the guarantor of this study. He had full access to all the data in the study and had final responsibility for the decision to submit for publication. Maria B Ospina designed the study, oversaw its conduct, and prepared the report with input from all authors. Dr Brian H Rowe, Dr Donald C Voaklander and Maria B Ospina secured funding for this research. Maria B Ospina undertook the literature searches, study assessment, data abstraction and analysis. Dr Brian $\mathrm{H}$ Rowe, Maria Ospina, Dr Donald C Voaklander, Dr Michael K Stickland, Dr Malcolm King and Dr Ambikaipakan Senthilselvan contributed to study design, data interpretation and writing of the report. All of the authors approved the final version of the manuscript for publication. The authors thank Dr Laura Reyes, Jennifer Seida and Dr Cristina Villa-Roel for their help with study assessment. 


\section{COMPETING INTERESTS: None declared.}

FUNDING: Ms Ospina is supported through a PhD Studentship Award from the Canadian Thoracic Society and the Canadian Lung Association. Dr Stickland is supported by New Investigator Salary Awards from the Heart and Stroke Foundation of Canada (HSFC) and Canadian Institutes of Health Research (CIHR) both in Ottawa, Ontario. Dr King is the Scientific Director of the CIHR Institute of Aboriginal Peoples' Health. Dr Rowe's research is supported by a Tier I Canada Research Chair in Evidence Based Emergency Medicine from the CIHR through the Government of Canada.

\section{REFERENCES}

1. Global Initiative for Asthma (GINA). Global strategy for asthma management and prevention (Updated 2010) 2010. <www.ginasthma.org> (Accessed March 3, 2010).

2. Lopez AD, Shibuya K, Rao C, et al. Chronic obstructive pulmonary disease: Current burden and future projections. Eur Respir J 2006;27:397-412.

3. Chapman KR, Mannino DM, Soriano JB, et al. Epidemiology and costs of chronic obstructive pulmonary disease. Eur Respir J 2006;27:188-207.

4. Hubbard R. The burden of lung disease. Thorax 2006;61:557-8.

5. British Thoracic Society The burden of lung disease: A statistical report from the British Thoracic Society, 2nd edn. London: British Thoracic Society, 2006. <www.brit-thoracic.org.uk/Portals/0/ Library/BTS\%20Publications/burdeon_of_lung_disease2007.pdf> (Accessed March 5, 2011).

6. Marmot M. Social determinants of health inequalities. Lancet 2006;365:1099-104.

7. Evans T, Whitehead M, Deiderichsen F, et al, eds. Challenging Inequities in Health: From Ethics to Action. New York: Oxford University Press, 2001.

8. Link BG, Phelan J. Social conditions as fundamental causes of disease. J Health Soc Behav 1995;35:80-94.

9. Adelson N. The embodiment of inequity: Health disparities in aboriginal Canada. Can J Public Health 2005;96:S45-61.

10. Stephens C, Porter J, Nettleton C, et al. Disappearing, displaced, and undervalued: A call to action for Indigenous health worldwide. Lancet 2006;367:2019-28.

11. MacMillan HL, MacMillan AB, Offord DR, et al. Aboriginal health. CMAJ 1996;155:1569-78.

12. Young TK. Review of research on aboriginal populations in Canada: Relevance to their health needs. BMJ 2003;327:419-22.

13. Gracey M, King M. Indigenous health part 1: Determinants and disease patterns. Lancet 2009;374:65-75.

14. Smylie J, Anderson I, Ratima M, et al. Indigenous health performance measurement systems in Canada, Australia, and New Zealand. Lancet 2006;367:2029-31.

15. Bird ME. Health and indigenous people: Recommendations for the next generation. Am J Public Health 2002;92:1391-2.

16. Tramer MR, Reynolds DJM, Moore RA, et al. Impact of covert duplicate publication on metaanalysis: A case study. BMJ 1997;315:635-40.

17. Loney PL, Chambers LW, Bennett KJ, et al. Critical appraisal of the health research literature: Prevalence or incidence of a health problem. Chronic Dis Can 1998;19:170-6.
18. Landis JR, Koch GG. The measurement of observer agreement for categorical data. Biometrics 1977;33:159-74.

19. DerSimonian R, Laird N. Meta-analysis in clinical trials. Control Clin Trials 1986;7:177-88.

20. Hedges LV, Olkin I. Statistical methods for meta-analysis. Orlando: Academic Press, 1985.

21. Deeks J, Altman D, Bradburn M. Statistical methods for examining heterogeneity and combining results from several studies in meta-analysis. In: Egger M, Smith G, Altman D, eds. Systematic Reviews in Health Care: Meta-Analysis in Context, 3rd edn. London: BMJ Publishing Group 2003:285-312.

22. Higgins JP, Thompson SG. Quantifying heterogeneity in a metaanalysis. Stat Med 2002;21:1539-58.

23. Salmond C, Crampton P, Hales S, et al. Asthma prevalence and deprivation: A small area analysis. J Epidemiol Community Health 1999;53:476-80.

24. Lewis S, Hales S, Slater T, et al. Geographical variation in the prevalence of asthma symptoms in New Zealand. N Z Med J 1997;110:286-9.

25. Crane J, Lewis $S$, Slater $T$, et al. The self reported prevalence of asthma symptoms amongst adult New Zealanders. N Z Med J 1994;107:417-21.

26. Bremner PR, de Klerk NH, Ryan GF, et al. Respiratory symptoms and lung function in aborigines from tropical Western Australia. Am J Respir Crit Care Med 1998;158:1724-9.

27. Garner R, Carrière G, Sanmartin C. The health of Inuit, Métis and First Nations adults living off-reserve in Canada: The impact of socio-economic status on inequalities in health. Health Research Working Paper Series Catalogue no 82-622-X - No. 004. Ottawa: Statistics Canada, 2010.

28. Gorman BK, Chu M. Racial and ethnic differences in adult asthma prevalence, problems, and medical care. Ethn Health 2009; 14:527-52.

29. Janz T, Seto J, Turner A. Aboriginal Peoples Survey, 2006: An overview of the health of the Métis population. Health Research Working Paper Series; Catalogue no. 89-637-X - No. 004. Ottawa: Statistics Canada, 2009.

30. Loveland KM, Kessler AC, Helgerson SD, et al. Is there a disparity in the prevalence of asthma between American Indian and white adults? J Asthma 2008;45:557-60.

31. Pleis JR, Barnes PM. A comparison of respiratory conditions between multiple race adults and their single race counterparts: An analysis based on American Indian/Alaska Native and white adults. Ethn Health 2008;13:399-415.

32. Veale AJ, Peat JK, Tovey ER, et al. Asthma and atopy in four rural Australian aboriginal communities. Med J Aust 1996;165:192-6.

33. Australian Bureau of Statistics and the Australian Institute of Health and Welfare. The health and welfare of Australia's Aboriginal and Torres Strait Islander peoples 2005. Cat. no. IHW 14. Canberra: AIHW, 2005. <www.aihw.gov.au/publicationdetail/?id=6442467754> (Accessed March 10, 2011).

34. Hill K, Barker B, Vos T. Excess Indigenous mortality: Are Indigenous Australians more severely disadvantaged than other Indigenous populations? Int J Epidemiol 2007;36:580-9.

35. Aaron SD, Vandemheen KL, Boulet L-P, et al. Overdiagnosis of asthma in obese and nonobese adults. CMAJ 2008;179:1121-31.

36. Global Initiative for Chronic Obstructive Lung Disease (GOLD). Global strategy for the diagnosis, management, and prevention of chronic obstructive pulmonary disease (Updated 2010) 2010. $<$ www.goldcopd.com> (Accessed March 2010). 


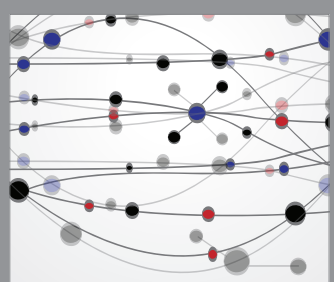

The Scientific World Journal
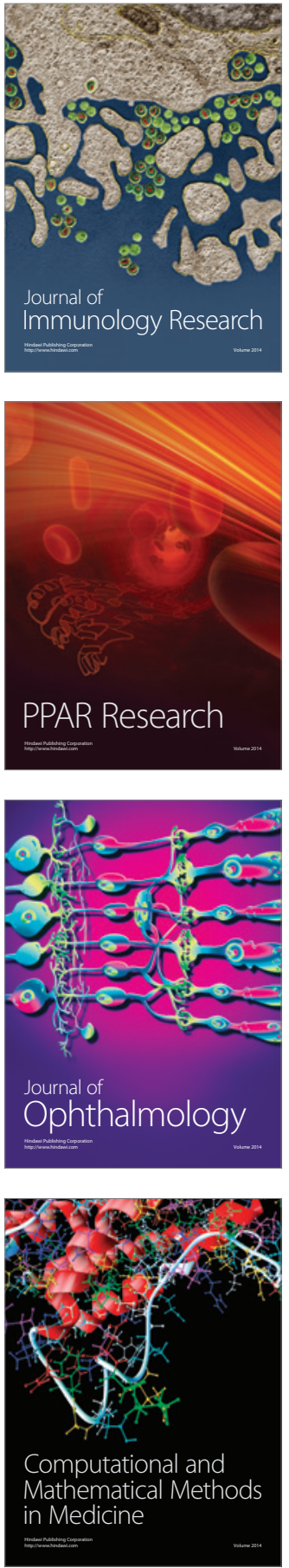

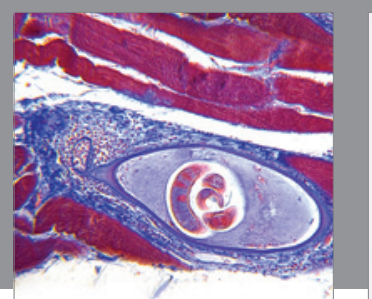

Gastroenterology Research and Practice

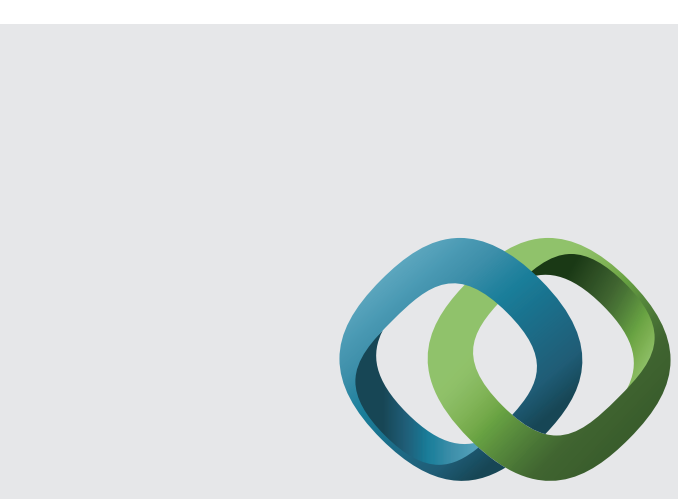

\section{Hindawi}

Submit your manuscripts at

http://www.hindawi.com
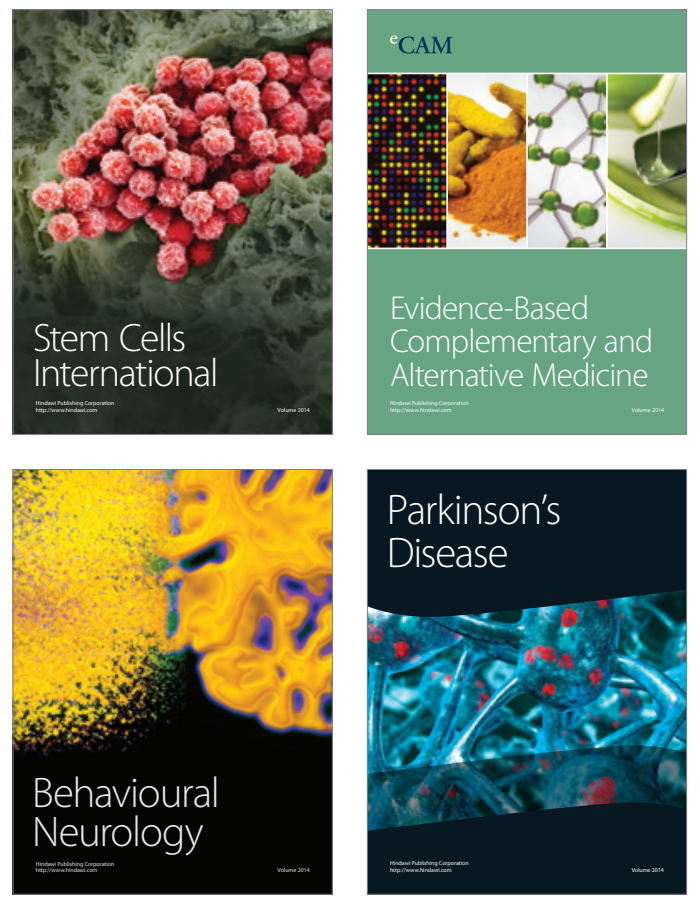
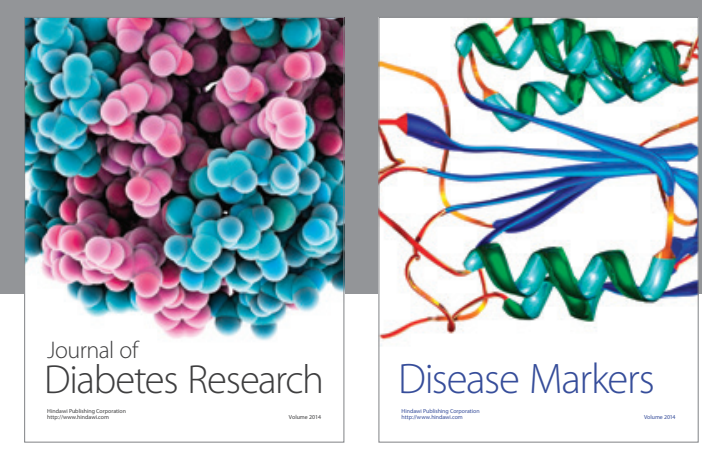

Disease Markers
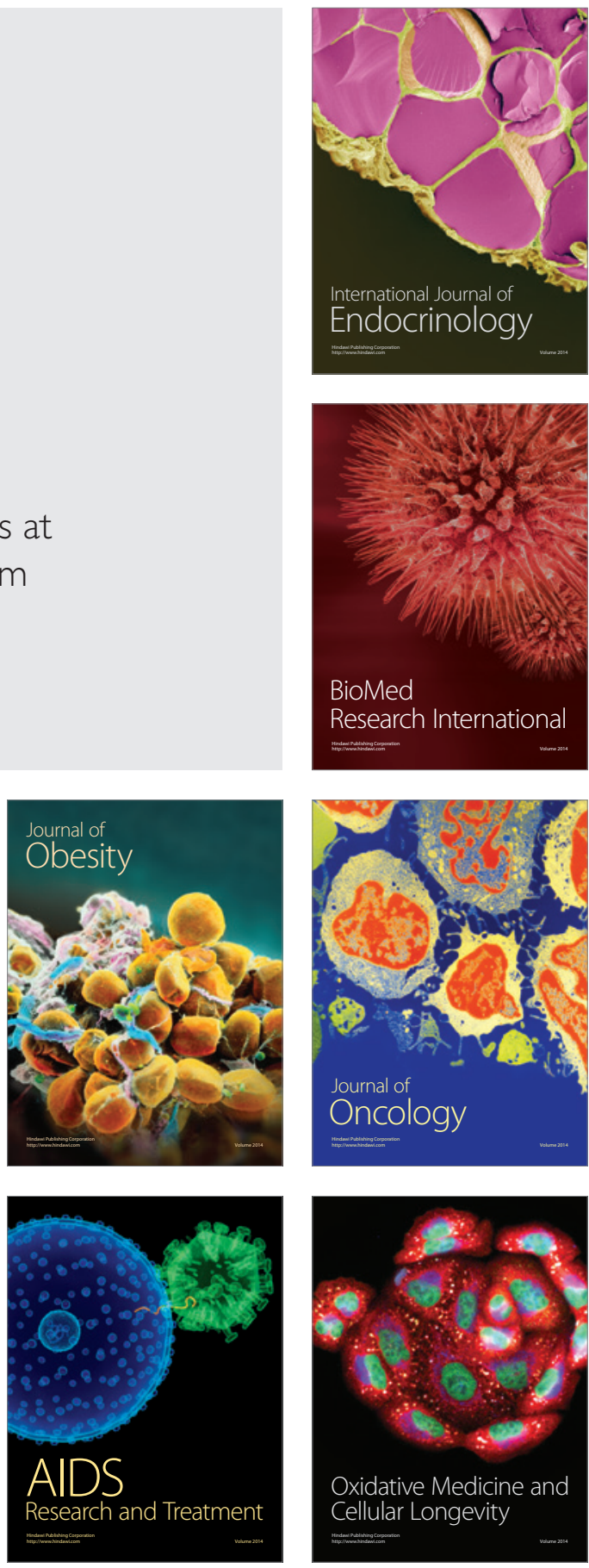